\title{
Dear Santa: The effects of television advertising on young children.
}

Running Head: The effects of television advertising

Karen J. Pine and Avril Nash,

Psychology Dept.,

University of Hertfordshire,

College Lane,

Hatfield,

Herts.U.K.

AL10 9AB

Email: K.J.Pine@herts.ac.uk

Telephone: 01707284000

Fax: 01707285073 


\section{Dear Santa: The effects of television advertising on young children.}

\section{$\underline{\text { Abstract }}$}

Every day children are exposed to the selling messages of advertisers via the television. There is some debate in the literature over the age at which young children can distinguish television advertisements from programmes, when they can remember and want what they see and when they are able to understand that the advertiser's motive is to sell a product. Resolution of the debate has been hampered by methodological difficulties and paradigms which fail to fully capture and explain children's responses to advertisements. This study uses a novel and ecologically valid method of measuring how toy advertising affects children by studying their requests to Father Christmas, monitoring toy commercials and collecting television viewing data. Eighty three children aged from 4.8 to 6.5 years, who had written letters to Father Christmas, were interviewed regarding the extent and nature of their television viewing. Letters and similar data were also analysed for 16 nursery school children, aged 3.8 to 4.8 years, using questionnaire responses from their parents. Overall, children who watched more commercial television were found to request a greater number of items from Father Christmas. These children also requested more branded items than children who watched less. However, the children's requests did not correlate significantly with the most frequently advertised toy products on television in the buildup to Christmas. Almost $90 \%$ of the toys advertised did not feature once in the children's letters, suggesting that recall for specific brand names is poor in the under-sevens. A positive correlation was found between watching television alone and number of requests, suggesting that lone viewing may render children more susceptible to advertising. A comparison group of children from Sweden, where advertising to children is not permitted, asked for significantly fewer items. The data suggest that English children who watch more TV, and especially those who watch alone, may be socialised to become consumers from a very early age. 


\section{$\underline{\text { Introduction }}$}

Television is a major part of children's lives in the Western world today. In the UK children spend an average of two and a half hours each day watching TV and 63\% have their own TV set (Livingston \& Bovill, 1999). Three of the five terrestrial channels carry advertising and, within certain limits, advertisements can be aimed directly at children. What effect is increasing exposure to television advertising having upon children in the UK today? This paper is concerned particularly with younger children, below the age of 7 years, and is aimed at determining how receptive they are to the commercial messages of toy advertisers.

It has been argued that, due to their limited memory capacity, young children may not recall advertisements and therefore will be relatively immune to advertisers' messages (Macklin, 1994). Others claim that having a lack of cognitive mechanisms to defend themselves actually renders children more susceptible to persuasive messages. Furthermore, there is a question mark over whether very young children can distinguish advertisements from programmes. Levin, Petros \& Petrella (1982) found that children as young as 3 were able to make the distinction but had no understanding of selling motives of advertisers. Levin et al. say that it is not until 8 years old that children begin to understand the selling purpose of an advertisement. Prior to this children regard advertisements as simply announcements designed to help, entertain or inform viewers. In making the decision not to allow advertising aimed at children, the Swedish government relied on evidence from sociologist Erling Bjurstrom that it is not until 12 years of age that all children can distinguish advertisements and understand the selling motives of the advertiser.

Being able to recognise that advertisements differ from programmes appears to emerge early on in development, whereas the kind of healthy skepticism which is needed to resist 
commercial pressure requires far more sophisticated levels of understanding. The cognitive skills which children lack, i.e. understanding of persuasive intent, consumer literacy and perception of realism are discussed further here.

\section{Understanding of persuasive intent}

Young children do not realise that a message can portray only positive information, whilst withholding negative information, in order to manipulate another's mental state (AloiseYoung, 1993; Bennett \& Yeeles, 1990). For example, in the Aloise-Young study, children were asked to present a description of themselves in order to get picked for a fictitious team. Younger children included negative as well as positive information, whereas older children were better at self-promotion and included only positive descriptions. Eight year olds’ ability to selectively self promote suggests that this is the age when children are also able to appreciate that advertisers try to influence us with persuasive messages. A lack of this awareness in younger children, resulting in higher trust in the advertiser, renders them more vulnerable to selling messages. Allied to this is the authoritative status of television messages for young children, who believe that adults do not lie and the younger the child is, the more likely they are to believe that advertisements always tell the truth (Greenberg, Fazal \& Wober, 1986). In a review of the literature, Dorr (1986) found that it is between 7 and 9 years that children understand the persuasive intent of television advertising.

\section{Consumer literacy}

Young children have a limited understanding of commercial markets, and are unaware that advertisements are motivated out of a desire for profits. Somewhat surprisingly, Greenberg et al. (1986) claimed to have found that $80 \%$ of 4 - to 13 -year old children knew that advertisements 'wanted to sell you something', with no variation by age. In a study by Gaines \& Esserman (1981) however, only 1\% of 4- to 5-year olds realised that the goal of an advertisement was 'to try and make you buy things', rising to $28 \%$ in 6- to 8- year olds. Clearly, 
the type of question asked in these studies elicited different results but when Ward, Wackman \& Wartella (1977) asked 11- to 12-year olds to explain the selling and profit motives of advertisers only $25 \%$ were able to do so, suggesting that real consumer literacy emerges in early adolescence. Younger children, who do not know that selling implies an exchange of money for goods (and an opportunity for profit), are unlikely to recognise advertisers' motives (Henricksen, 1996). Therefore, it is probably around age 13 or 14 that young people understand consumer markets and acquire a healthy skepticism towards the truthfulness of product claims (Linn, de Benedictis \& Delucchi, 1982; Robertson \& Rossiter, 1974).

\section{Perception of realism.}

In television commercials techniques are frequently employed to enhance the appearance of a product. Adults know that the sparkle on the newly-cleaned floor in the TV commercial is unlikely to be matched in reality. But before the age of four or five children are more heavily affected by production factors and do not understand that appearances can differ from reality. Two and three year olds, in fact, believe that images on TV screens reflect real objects inside the set (Flavell, Flavell, Gree \& Korfmacher, 1990; Huston \& Wright, 1998). In Flavell's study he found that these young children believed a bowl of popcorn would spill if the set was turned upside down. And when Jaglom and Gardner (1981) showed two and three year olds an egg breaking on television, the children tried to clear it up. This reality perception is important because television that is perceived as real has a greater impact on children than if it is judged unreal (Berry \& Asamen, 1993). Without an awareness of production techniques and the representational nature of television, young children will believe that a product is exactly as it appears and not realise that the advertisement was created to promote it in the best possible way. After the age of four children develop the cognitive skills, including a theory of mind, which helps them to distinguish reality from fantasy.

Thus a number of strategies and cognitive abilities need to be in place before the child is 
fully aware of the selling motives of the advertiser. Evidence from psychological studies suggest that these abilities emerge at different points in development and that full understanding of advertisers' motives is likely to be a process which takes a number of years. Parents have a role to play in this. By watching television with their child they can help them to understand advertisers' motives and the difference between appearances and reality, thus neutralising some of the powerful messages their children are exposed to. There is little reliable data available on co-viewing although it has been found that children who watch more commercial television had parents who were less concerned about the negative effects of watching television and perceived less need to control their child’s viewing (Gunter \& McAleer, 1997).

Nonetheless, children's lack of awareness about the motives of television advertisers does not prevent the commercial messages influencing their preferences and, as suggested, may render the child more susceptible. For the advertiser, a successful advertisement is one which is memorable since there is usually a delay between seeing an advertisement and remembering to buy, or request, the product. Children's memory for advertisements is a very complex issue and one which has been investigated using a variety of methodologies. These include diary methods (Greenberg et al., 1986), surveys which rely on free recall and ask about requests to parents (Robertson \& Rossiter, 1976), and experimental studies which test children's recognition of advertised products (Hite \& Hite, 1994; Macklin, 1994; Sharp et al., 1976). Discrepancies in the results of studies into the age at which children can remember television advertisements may be due to the limitations of each of these methodologies. Surveys suffer from lack of verification of the information gained and the fact that children are often over-concerned with giving the 'right' answers. Younger children are also likely to be unable to recall brand names which, nonetheless, may still have left a memory trace. Studies which test recognition of products get around this problem, usually by employing a forced choice test, but these have usually been conducted in laboratory settings and suffer from a lack of ecological validity. Both types of studies fail to successfully emulate the time lapse that can occur between exposure to an advertisement and its recall, or to recreate the type of context in which children typically express a product preference. 
The current study looks at the impact which toy advertising, in the run-up to Christmas, has upon children below the age of seven. As the literature has shown, this is the age group who are likely to have higher trust, lower recall and lower understanding of commercial messages than older children. This would lead us to expect these children to have a high vulnerability to advertising, although perhaps with a low recall of brand names. The study also employs a novel method which overcomes many of the methodological limitations of earlier research. It assesses the effects of toy advertising by looking at a behaviour which many children engage in spontaneously, asking for toys in a letter to Father Christmas. Thus it overcomes the lack of ecological validity which laboratory experiments suffer from, since virtually all children in the UK write a letter to Santa each year. Furthermore, it is less subject to the failings of survey methods where misunderstandings about questions can produce inaccurate data. By collecting children's letters at the beginning of December, when toy advertising has been intensifying for a number of weeks, the study also makes use of the real time frame between exposure to the advertisements and the making of requests. It also goes beyond measuring which advertised products children recognise or recall and tells us what they actually want. Finally, it is not complicated by the financial status of the children's parents. Children from poorer families may have been socialised not to ask their parents for expensive toys, yet may feel these constraints do not apply to their requests to Santa.

By looking at the under-sevens' requests in their letters to Santa, and also obtaining a measure of their television viewing habits, this study therefore aims to discover whether there is a relationship between young children's exposure to commercial television and requests for advertised products. The data on viewing habits also reveal whether children watch alone or with a parent and whether this affects their susceptibility to advertising. By comparing letters written by children in the UK with those written by Swedish children it also asks whether their ban on toy advertising means that children ask for less.

Method 
$\underline{\text { Design }}$

A correlational design was used to examine the relationship between the amount of television watched, and in particular commercial television, and the proportion of branded products requested by children in their letters to Father Christmas. The two principle variables were a television score (calculated from responses to a questionnaire) and the proportion of branded products. Branded or brand name products referred to in this report are those which are marketed under a proprietary trade mark or registered name, e.g. Barbie, as opposed to a generic term, e.g. doll. The overall relationship was examined, as were relationships using classifying variables of age, access to cable or satellite television and whether or not the child watched television with adult.

Another correlational analysis considered the relationship between children's requests and products advertised on children's television (ITV) during the six week period prior to the children writing their letters.

A between groups design was used to compare the proportion of branded items requested by the UK children with that of kindergarten children in Sweden, where toy advertising aimed at children is banned.

It was predicted that (a) there would be a significant relationship between the television score and the proportion of branded products requested by the UK children in their letters to Father Christmas, i.e. that a higher television score would indicate a higher proportion of branded products requested. It was also predicted that the relationship between the two variables would be influenced by (b) the children's age, (c) regular access to satellite or cable television and (d) watching with an adult. It was further predicted that (e) there would be a relationship between the frequency of television advertisements and the branded products requested and (f) there would be significant differences between the amount of branded products requested by the UK children and the Swedish children. 


\section{$\underline{\text { Participants }}$}

A total of 118 children took part in the study. The U.K. sample were recruited from a nursery school in Bedfordshire, the Reception and Year 1 classes of two primary schools in Hertfordshire and an infants' school in the London Borough of Barnet. The overall mean age of the children was 5,5 years ( $\underline{\mathrm{sd}}=8.59 \mathrm{mths})$ and the sample comprised 45 boys and 54 girls.

The UK sample was composed as follows:

Nursery children: $n=16$. Ages 3,8 to 4,8 years. Mean age 4,2 years ( $\underline{\mathrm{sd}}=3.7 \mathrm{mths}$ )

School children: $\quad n=83$. Ages 4,8 to 6,5 years. Mean age 5,8 years ( $\underline{\mathrm{sd}}=5.6 \mathrm{mths}$ )

For the purposes of this study they were then sub-divided further into age groups as follows:

Group 1: 3,8 to 4,8 years ( $n=16$; mean age 4,2 years, $\underline{\mathrm{sd}}=3.72$ months)

Group 2: 4,8 to 5,6 years $(\mathrm{n}=41$; mean age 5,3 years, $\underline{\mathrm{sd}}=2.84$ months)

Group 3: 5,7 to 6,5 years $(n=42$; mean age 6,2 years, $\underline{\mathrm{sd}}=2.98$ months)

Group 1 represents the nursery school group. As the television scores for these children was derived from parental report this group is considered separately for some of the analyses. The other two groups are representative of Reception and Year 1 classes. The overlap in age groups between Groups 1 and 2 occurs because there was one child aged 56 months at school.

Head teachers and parents consented to the children participating in the study. The final figure of 118, above, takes into account 9 parental withdrawals for religious (7), educational (1) or other (1) reasons; and 2 instances where children declined to take part.

The sample size was chosen as a result of a priori power calculations using $\underline{G}$ Power (Faul \& Erdfelder, 1992). Based on the ITC report which suggests a strong effect of advertising, an effect size of $r=0.5$ was used. With alpha $=.05$ and power $=.95$, a sample of 34 participants is recommended for a one-tailed correlation.

The Swedish sample, Group 4, comprised 19 kindergarten children (9 girls and 4 boys). They were all 6 years old. Letters were obtained after contacting a pre-school in Nacka, Sweden 
but no interviews were conducted.

$\underline{\text { Materials }}$

The letters to Father Christmas were written on paper provided by each individual school and this varied from school to school: in some it was printed with a seasonal decoration, in others it was decorated by the children themselves and one school provided areas on the paper for the children to both write and draw their requests. The Swedish children all drew their requests which were then labelled. Either the original letter or a photocopy was used for analysis.

The questionnaire used for the structured interview with Groups 1, 2 and 3, was constructed to provide information about the children's viewing habits in order to establish a TV score for each child and gather information.

\section{Construction of the questionnaire}

1. Do you watch children's television?

This acted as an introductory question to the rest of the interview.

2. How often do you watch?

Do you watch children's television when you go home after school? Is that :

Everyday / A lot of days / Just some days?

What about before you come to school in the morning (when you get up)? Is that

Everyday / A lot of days / Or just sometimes?

Do you watch on a Saturday morning? Yes / Sometimes / No

On a Sunday morning? Yes / Sometimes / No

Question 2 was designed to reflect how much children's television the child watched, specifically, after school, before school and at weekends. Television programmes in the U.K. aimed at children on ITV (CITV) cover a period of 1.75 hours each weekday 15.15-17.00 hours, 3.5 hours on a Saturday (08.00-11.30 hours) and 1.5 hours on a Sunday (08.00-09.30). 
Responses to the various sections of question were scored to reflect these hours proportionately. $\underline{\text { 3. Do you have a favourite programme, something you like watching best? }}$ This was designed as an interest question to stimulate the children's thoughts about television programmes that they watch.

\section{Do you ever watch: The Forgotten Toys / Sooty / Kipper / Art Attack / Sabrina / Diggit}

\section{/SM:TV Live?}

In order to examine how much commercial television the children watched ITV, or CITV as the children's programming is termed, was chosen as being the most accessible channel to all UK children. The programmes given as examples in this question were from this channel and were selected as being representative examples of children's television viewing in the afternoon, after school or at the weekend. The programmes selected were considered suitable for a range of age groups (e.g. The Mopatops Shop for younger children and Sabrina, the Teenage Witch for older children).

\section{$\underline{5 .}$ Do you know what adverts are? Can you tell me about them?}

$\underline{6 .}$ Do you watch the adverts? OR Do you ever see Barbie( or Action Man) on the telly, do you watch them when they're on?

Questions 5 and 6 looked at whether the child knew what an advertisement was and whether s/he paid attention to them. Following a pilot study, Question 6 was modified (from 'Do you watch them?') in order to allow for a negative response to Question 5. Thus, if a child responded 'no' to question 5, then question 6 would be phrased, 'Do you ever see Barbie or Action Man on the telly, do you watch them when they're on?' as these products are only seen in advertisements.

\section{Do you watch TV on your own or with a grown up, someone like mum or dad?}

This question established whether the child watched alone or with a parent as previous research 
has suggested this affects how children process television’s messages.

8. Think about the televisions there are in your house, can you tell me how many there are? Question 8 was designed to discover whether the children had access to more than one television, thus increasing their overall access to commercial television.

9. Do you ever watch any of the satellite or cable TV channels (e.g. Nickelodeon, Disney Channel, Cartoon Network)? Is that at home?

Question 9 sought to discover whether the child had regular increased access to commercial television in the form of satellite or cable broadcasting.

10.Do you do any after-school activities regularly (every week)? For example, swimming, dance, clubs, gym, football, etc.? How often/many days in the week?

Finally, question 10 sought to establish whether regular extra curricular activities curtailed viewing and the score for this item was designed to be subtracted from the sum of scores from questions 2 and 4 to give a final 'TV score'.

The children's interview questionnaire was also distributed, in a modified form to the parents of the nursery children. Besides amending the wording of the questions in order to ask the parent about the child, since the children were considered too young to self-report, question 5 was modified to ascertain whether the parent thought that the child made some distinction between advertisements and programmes. A further question was added to establish how often the child attended nursery (i.e. number of morning or afternoon sessions) as this would affect the amount of exposure to children's television, since television was not watched at nursery. As with the extra curricular activities, the number of afternoon nursery sessions was designed to be deducted from the sum of questions 2 and 4. As the questionnaire was designed to elicit information rather than attitude no response order bias were deemed necessary.

Photocopies of the letters written by Swedish children were also used for analysis. 
Translations were carried out by a Swedish person studying in England and an English person residing in Sweden.

The interviews with the children were recorded using an Olympus S711 Micro cassette Recorder. Television programmes and advertisements were recorded using a Panasonic NV HD640 video recorder.

\section{$\underline{\text { Procedure }}$}

Video recordings were made of a selection of children's ITV viewing between 23.10.99 and 28.11.99. This comprised 6 Saturdays from 8.00 a.m. to 11.30 a.m., 5 Sundays from 8.00 a.m. to 9.30 a.m. and two weekdays per week, chosen at random, from 3.15 to 5.00 (Tuesday n = 3; Wednesday $n=2$; Thursday $n=3$; Friday $n=3$ ), giving a total of nearly 50 hours of children’s commercial television.

In order to keep the study as naturalistic as possible, and thereby maintain external validity, the teachers at the schools and nursery were asked to proceed as they would normally do in asking the children to write their letters to Father Christmas. It was agreed that this would occur at some point convenient to the teachers in the week beginning 29th November. No experimenter was present. Children were assisted by the teachers, where necessary, with spelling and writing. In the case of the nursery the children were asked to dictate their letter to a nursery teacher or nursery nurse who wrote it out in highlighter so that the child could write over it. The original letters or photocopies of these were used for the study. See Figure 1 for some examples of children's letters.

\section{Insert Figure 1 about here}

All interviews were conducted during the first three weeks of December after the children had written their letters to Father Christmas. The interviews were preceded by a brief explanation and time to settle the child, then each interview followed the questionnaire closely. 
At the end of the interview each child was thanked for his or her assistance.

The children in Sweden were asked by their teachers to send a letter to Father Christmas with their Christmas requests. Photocopies of these were used for the study.

\section{$\underline{\text { Results }}$}

The results of the study are divided into four parts. The first section considers an analysis of the questionnaire data and the second examines the relationship between television viewing and the proportion of branded products requested by children in their letters to Father Christmas. The third section then looks at the relationship between those branded items requested and those advertised on television and, finally, the fourth section compares requests made by UK school children with those made by a contrast group of Swedish nursery children.

\section{Section 1: Analysis of questionnaire data}

In this section it is important to note that the source of the questionnaire data for one of the three groups, i.e. the nursery group, is parental report whereas the source for the other two groups is self-report. Therefore the analysis of this data will be carried out in two parts, commencing with the self-reported school children's data. The information will then be combined to give overall means and any differences which arise as a result of these alternative sources will be examined. In general, even where the distribution has not been normal, parametric inferential tests have been carried out on the data. However, due to the very varied, non-normal distribution of the parental report, or nursery children's, data non-parametric tests have been used for inferential statistics in that instance.

Television scores were calculated by summing the scores for responses to questions number 2 (3 parts) and 4: this indicated how much television and, in particular, how much commercial television, the children watched. From this figure was deducted the number of days of after-school activities and, in the case of the nursery children, the number of afternoon sessions attended, since these would prevent the child from watching afternoon children's television. The result was an individual television score for each child. Construct validity was 
evaluated by correlating the response scores with the total TV score. Positive, reliable Pearson correlations were found for questions 2 and 4, a total of four response scores. (Q1a: $\underline{r}=.615$; Q1b: $\underline{r}=.333 ;$ Q1c: $\underline{r}=.760 ;$ Q2: $\underline{r}=.640$; in all cases, $\underline{\mathrm{n}}=99, \mathrm{p}<.05)$. Question number 8 concerning the number of televisions per household was discarded after internal consistency checks failed to produce a reliable correlation $(\mathrm{p}>.05)$.

School children (self-report data)

Amount of TV Viewing: TV scores for this sample produced a negatively skewed distribution with no outliers. The mean TV score $(\underline{\mathrm{n}}=83)$ was $9.68(\underline{\mathrm{sd}}=3.709)$; scores ranged from a minimum of 0 to a maximum of 15 . The mean television scores analysed by gender and by age. A two-tailed between groups ANOVA found no reliable main effects on TV score for either age or gender $(\mathrm{p}>$.05). However, there was a two-way interaction between age and gender. As Figure 2 shows younger girls (55-66 months) had significantly higher TV scores than boys of the same age but the situation was reversed for the older children (67-77 months). This interaction was confirmed as reliably different in a two-way Anova, $\underline{F}(1,81)=4.082, \underline{p}=.047$.

\section{Insert Figure 2 about here}

Knowledge about advertisements: The question 'Do you know what an advert, or advertisement, is?’ produced 56 negative responses and 27 positive responses from the sample of 83 school children. However, of those who said that they did know what an advertisement was only 16 were able to define it in such a way that it was clear that they knew the difference between an advertisement and a programme. The other 11 were unable to explain that an advertisement was different or offer an example of one. Equally, of the 56 who said that they did not know what an advertisement was, further probing in relation to question 6 found that 11 of these children were able to offer an explanation which showed that they were able to make the distinction. Some of the children also mentioned the selling aspect of the advertisement. Missing data (10 missing values in total) in response to question 6 arose as a result of the original wording of the question which was corrected after piloting. Of the 73 children who did respond 55 (66.3\% of the total 
sample) appeared to watch advertisements and 18 (21.7\%) responded that they either did not watch advertisements, or more specifically, Barbie or Action Man advertisements.

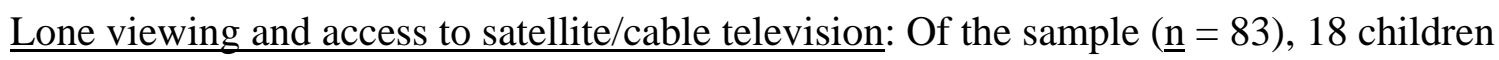
(21.7\%) regularly watched television with an adult (parent), 31 (37.3\%) sometimes watched with an adult and 34 (41\%) watched either on their own or with a sibling. Fifty two children (62.7\%) had home access to satellite or cable television channels.

\section{Nursery school data (parental report)}

Amount of TV Viewing: TV scores for the nursery children appeared to be not normally distributed and this was confirmed in a Shapiro Wilks test for normality $(\underline{W}=.849, \underline{p}=.013)$. The mean TV score for this sample $(\underline{\mathrm{n}}=16)$ was $5.375(\underline{\mathrm{sd}}=3.6674)$ and the mode was 8 . TV scores ranged from a minimum of 3 to a maximum of 9 . The mean television scores were analysed by gender using a two-tailed Mann Whitney $U$ test and no reliable main effects of gender were found for TV score $(\mathrm{p}>.05)$.

A comparison of the difference in mean TV viewing scores of the school children and nursery school children, shown in Figure 3, was found to be significant in a Mann Whitney U test $(\underline{\mathrm{U}}=257, \underline{\mathrm{p}}=<.01)$. This suggests that the nursery school children watched significantly less TV than the school children. However, it may be due to the sources of the data, with parental report data resulting in a far lower mean TV score than the self-report data.

\section{Insert Figure 3 about here}

Knowledge about advertisements: In response to the questions about understanding and watching advertisements, 9 parents considered that their child did understand that advertisements were different to programmes whilst 6 parents were uncertain of their child’s knowledge. Only 1 parent felt that their child could not make the distinction between programmes and advertisements.

Lone viewing and access to satellite/cable television: According to the parental reports, 7 (44\%) of the nursery school children regularly watched television with an adult and 9 (56\%) sometimes watched with an adult. According to their parents, none of the children in the nursery group 
watched television regularly without an adult. Of the sample $(\underline{\mathrm{n}}=16), 9(56.3 \%)$ had regular/home access to satellite or cable television channels.

This suggests that the nursery school children were less likely to watch alone than the school children, although the source of the data (parental report vs self) report may account for some of this difference. The difference is confirmed as significant in a Pearson chi-square $\underline{\mathrm{X}^{2}}$ $(\underline{\mathrm{n}}=99)=10.33, \underline{\mathrm{p}}=<.01$. The implications on reliability will be explored in the discussion.

Data from nursery and school-children (combined)

TV Viewing data: When data from both sources was combined $(\underline{\mathrm{n}}=99)$ this produced a negatively skewed distribution with two outliers (values: -1, -3). As the primary purpose of the study was to examine relationships rather than compare means, these outliers were retained in the data set. The overall mean TV score was $8.99(\underline{\mathrm{sd}}=4.014)$. Viewing data related to access to satellite/cable TV: Overall mean TV scores for those without home access to cable or satellite television $(\underline{\mathrm{n}}=38)$ was $7.658(\underline{\mathrm{sd}}=4.320)$ and for those with cable or satellite television $(\underline{\mathrm{n}}=61)$ the mean TV score was $9.819(\underline{\mathrm{sd}}=3.603)$. In a two-tailed independent groups t-test, this difference was found to be significant. $(\underline{\mathrm{t}}(97)=-2.687, \underline{\mathrm{p}}=<.01)$. As might be expected, given the extra choice of programmes afforded by non-terrestrial TV, those with access to satellite/cable TV had significantly higher TV viewing scores than those without.

\section{Section 2: Letters to Father Christmas and correlation with TV scores}

Requests by the children in their letters to Father Christmas were initially categorised as either non-branded/other goods and branded items, to enable a comparison between the amount of television watched and the amount of branded items requested. Items in the non-branded/ other group comprised a wide variety of items including such things as sweets, felt-tip pens, paints, dolls, teddy bears and computers. Various pets were also popular, ranging from hamsters to horses. 
A total of 307 items were requested by the sample $(\underline{n}=99)$ and of these 126 were branded items, i.e. 41\%. The mean number of items requested per child, both branded and nonbranded, was $3.10(\underline{\mathrm{sd}}=2.234)$ and the mean number of branded items per child was $1.273(\underline{\mathrm{sd}}=$ 1.185). An indication of the restrictions imposed by the children's underdeveloped writing skills on the number of requests made is clear when a comparison is made with the situation where the children at one of the UK schools were allowed to draw their requests $(n=34)$ : in this situation the number of items requested, branded and non-branded, ranged from 2 to 6 , with a mean number of total requests of $5.47(\underline{\mathrm{sd}}=2.24)$.

Almost three quarters $(73 \%)$ of the school and nursery children $(\underline{\mathrm{n}}=99)$ made a request for one or more branded products. Of these children, the maximum number of branded products requested was 5 (by 3 children) and the mode was 1 . The difference in means for both total requests and branded requests was not found to be significantly different by gender in two separate independent groups t-tests, $(\mathrm{p}>.05)$.

Examination of the data from the letters to Father Christmas highlighted an effect in this study which occurred as a result of the restricted writing and spelling ability of the children involved. Fifty-seven (57.6\%) of the total UK sample requested only one item and this occurred not necessarily because of a desire for only one item but simply because the children's writing and spelling abilities were insufficiently developed, and time constraints on teachers did not allow for them assisting with spellings of more than one item. Since children differed in the total number of requests made, the proportion of branded products requested was calculated by dividing the number of requested branded items by the total number of requests per letter. This resulted in a tri-modal distribution. The relationship between television score (TV score) and the proportion of branded items requested in the letter to Father Christmas was examined for the whole UK sample $(\underline{n}=99)$. In a one-tailed Pearson correlation no relationship between the two variables was found; there was no reliable effect of the TV score on the proportion of branded products requested, $\underline{\mathrm{r}}(97)=.054, \mathrm{p}>.05$. Thus, a higher TV score did not increase the proportion of branded products requested. 
Whilst one aim of the study was to examine the number of branded products requested in the context of overall requests, this places a range restriction on one of the variables, by making it proportional. Consequently this may have an overall effect of lowering the correlation. To examine whether this may be the case, another correlation was carried out examining the relationship between the TV score and the number of branded products requested. In this situation, the result of a Pearson one-tailed correlation was both positive and reliable, $\underline{\mathrm{r}}(99)=$ $.191, \mathrm{p}=<.05$.

Three further correlations were carried out. The first considered whether there was an influence of age on TV scores and the proportion of branded products. The second correlation examined whether access to cable or satellite television influenced Christmas requests. Neither of these was found to be significant.

The third correlation was concerned with whether watching television with or without an adult present had an effect. For this analysis, data from 'sometimes with adult' was discarded as being ambiguous and only those responses which indicated that the child watched 'mostly alone', or 'mostly with an adult', were considered. There was a positive and reliable correlation between watching television alone and the proportion of branded products requested Pearson correlation coefficient $\underline{\mathrm{r}}(2$ tailed $)=.364, \underline{\mathrm{p}}=<.05$. The correlation between watching television with an adult and the proportion of branded products requested was not significant, Pearson correlation coefficient $\underline{\mathrm{r}}(2$ tailed $)=-.177, \underline{\mathrm{p}}=>.05$. Thus lone viewing was related to higher requests for branded products.

Section Three: Analysis of brand name items requested and television advertisements

Branded items were categorised under their category brand name so, for example, a Barbie doll and a Barbie Caravan would come under the category 'Barbie’. Figure 4 shows a pie graph of all the requests made by the sample $(\underline{\mathrm{n}}=99)$. 
Further analysis of the branded products revealed that 27 requests were for media licensed or character merchandise products and another 20 requests were for electronic games or games machines. These, together with the top three requested items (Barbie, Furbies and Action Man), accounted for $92 \%$ of the branded products.

In the non-branded products, two generic terms accounted for $6.5 \%$ of the total number of requests (307): remote control car (8 requests) and baby doll (12 requests). No brand names were used for either of these products.

Over the period of nearly 50 hours, a total of 1388 advertisements appeared. The maximum number of advertisements in a weekend session was 127 on a Saturday and for a weekday session the maximum was 56 advertisements. In this section, the term 'advertisement' refers only to those commercials which were recorded on video for the purposes of this study; clearly there may well have been advertisements for other products at other times but the advertisements recorded were designed to act as a representative sample.

The 1388 advertisements comprised 175 (12.6\%) for food or drink products, 88 (6.3\%) for 'other' products such as washing powder, tissues, nappies, etc., and 24 (1.7\%) for fast food restaurants (McDonald's: 23; Burger King 1) The advertisements for McDonald's and Burger King Restaurants both promoted free gifts which were designed to appeal to children (i.e. models of Tarzan, Barbie or Hot Wheels cars), nevertheless for the purposes of this study they have not been included as ‘toy’ advertisements. The remaining 1101 advertisements (79.3\%) were for toys, these included computers or games consoles and associated games and children's videos.

In all 201 different toys were advertised. After collapsing within groups, i.e. amalgamating all the different products related to one brand name, for example Action Man or Lego, this figure reduced to 175 . The ten most frequently televised advertisements are listed in Table 1 together with the number of requests made by children for those products. 
In a one way Pearson test this correlation was found to be both positive and significant, $\underline{r}$ $(n=175)=.433, \mathrm{p}<.01$. This suggests a positive relationship between the frequency of a product advertisement and the number of requests for that product. However, this may be a spurious relationship as two outliers, Barbie and Action Man products, appear to be responsible for the strength of this relationship. If these two products are excluded from the calculation, then the one way Pearson correlation changes completely, finding no relationship between the two variables, $\underline{r}(\mathrm{n}=173)=.065, \underline{\mathrm{p}}>.05$. In fact, of the 175 advertisements, a total of $152(86.8 \%)$ products appeared for which no request was made.

With regard to those toys requested, Figure 5 shows the number of requests per item and also the number of televised recorded advertisements, if any, in the period 23.10.99 to the 28.11.99. Of the 27 media related or character merchandise products that were requested by the children, 9 were not advertised.

\section{Insert Figure 5 here}

\section{Children’s non-branded requests}

In relation to the use of generic terms i.e. remote control car and baby doll, analysis of the television advertisements found 21 advertisement for 7 individually named remote control cars, e.g. Hex Wheeler, Super Rebound, and 168 advertisements for 19 named baby dolls, e.g. Baby Expressions, My Sweet Love, thus suggesting that these advertisements may have created a desire for the products but no recall for the brand-name.

\section{$\underline{\text { Section 4: Comparison with a contrast Swedish group of children }}$}

The letters from the Swedish children $(\underline{\mathrm{n}}=19$ ) were analysed as before. The letters from a matched group from the English sample, who had also been allowed to draw their requests and whose age range matched those of the Swedish children (5 - 6 years old), were used for 
comparison purposes.

As Table 2 shows, the UK children requested more products generally than the Swedish children and this was confirmed as reliably different in a two-tailed independent groups t-test, $\underline{\mathrm{t}}$ $(51)=2.301, \underline{p}=<.05$. A two-tailed independent groups t-test of the difference in the mean number of branded requests between the UK children and the Swedish children approached but did not reach significance, $\underline{\mathrm{t}}(51)=1.815, \underline{\mathrm{p}}=.075$.

Insert Table 2 about here 


\section{$\underline{\text { Discussion }}$}

This study set out to examine whether the amount of television watched influences children's requests for toys. More specifically, it searched for a positive relationship between the amount of commercial children's television watched and the proportion of brand named toys requested in children's letters to Father Christmas. It looked further at whether this relationship was affected by other covariants such as age, increased availability of commercial television, in the form of satellite or cable television, and whether the presence of an adult when watching television mediated the effect.

The results of the study suggest that the proportion of branded products requested by children in their letters to Father Christmas is not influenced (a) by the amount of commercial television viewing; (b) by age, in this case across a range of three to six years; and (c) by increased access to commercial television in the form of cable and satellite television. However, by removing the range restriction imposed by proportional analysis, it appeared that children who watched more television, and commercial television in particular, were more likely to request not only more branded goods, but also more items generally. This shows how increased commercial television viewing encourages a more consumer orientated and materialistic nature, a finding which concurs with those of Ward et al. (1975), Robertson and Rossiter (1974) and Robertson et al. (1989). Moreover the fact that both the overall number of requests for toys and the number of requests for branded items increase, means that the proportion of branded products requested is likely to remain the same.

There was, as expected, an increased influence of advertisements when children watched the television on their own. This suggests that there is an effect of advertising on children which may be peculiar to their age and experience, confirming that the under-sevens are less resistant to the marketing intentions of advertisers and manufacturers when watching alone (Gunter et al., 1997; Young 1998; Bjustrom, 1994). Moreover the lack of effect by age among our sample suggests that six year olds have developed no more cognitive resistance to television 
advertisements than three year olds. Despite having acquired more cognitive skills by age six, particularly those relating to theory of mind and reality distinction, the older children were as susceptible as the younger ones. This emphasises the importance of the role that parents play in advertisement education and in helping their children to acquire critical viewing skills. Even preschool children have been found to be more advertising literate after being taught, within the family, about market place skills and the purpose of advertising (Hite \& Eck, 1987). Afterwards they were less susceptible to deception than those children in families who did not teach the same skills.

The novel use of letters to Father Christmas in this study emulates the typical delay that occurs between seeing an advertisement and the time of purchase or request, and lends ecological validity to these findings. Equally, construct validity appeared to be strong. However, the significant difference between the television scores for the school children (self-report) and the nursery children (parental report) requires further investigation. It may be that the scores accurately reflect the different viewing habits of the two groups of children. Alternatively it may be inaccuracy of memory on either part, elaboration in a desire to create a good impression or, in the case of parent report, a lack of awareness or underestimation of their child's viewing habits. As the wording of the questions was derived from the children, it is unlikely that the children's understanding of the wording is a problem. Whatever the cause, measures of television viewing habits employed in future studies need to pay particular attention to issues of reliability and accuracy.

A promising framework for understanding children’s memory for, and understanding of, advertisements involves applying a model based on implicit and explicit knowledge. This is explored well in Karmiloff-Smith's (1992) Representational Redescription model whereby knowledge is redescribed from an implicit non-verbalisable level through transitional stages to an explicit, and transferable, form (see also Pine \& Messer, 1999). The idea of having knowledge at different levels of explicitness also offers an explanation of previous findings whereby a variety of ages have been accredited with understanding of advertisements. A young 
child may not be able to explicitly define an advertisement but, implicitly, may be able to distinguish a commercial from a programme. Similarly, being able to tell what an advertisement is and understanding the objectives of the advertiser are two very different areas of knowledge. Children (and adults too) possess many dimensions of thought which are represented in a nonlinguistic form and television advertising is no exception. The challenge for researchers is to employ methodologies which tap into implicit and explicit knowledge in order to achieve a fuller awareness of how children's understanding of television develops.

In terms of the children's requests for branded products in relation to their total requests, $41 \%$ suggests either that children below the age of seven are not oriented towards brand names, that they do not understand the salience of the brand names or, as was predicted, that they simply have difficulty remembering them. Moreover, the $73 \%$ who requested one or more branded items is less than Greenberg et al.(1986) found. They issued diaries to children for completion during one week in October and found that $91 \%$ of heavy viewers of commercial television requested advertised products. Although these products included food and other items, rather than just toys, the lower number of requests found here may also reflect the normal delay that occurs between advertisement and moment of purchase.

In light of the number of advertisements for toys aimed at children and the large proportion of advertised products for which no request was made, there is a poor effect of many of the individual advertisements themselves. This is confirmed by the lack of a relationship between children's requests and televised advertisements after removing Barbie and Action Man from the analysis, the only two products for which there appears to be some effect. Collins \& Wellman (1982) identified a memory bias in young children, claiming they attend more closely to familiar content on television. As these two dolls have been on the market for a long time, and were popular with the parents of today's children, their familiarity may have reinforced the impact of the commercials. This suggests that advertisers of new products are at a huge disadvantage when it comes to trying to get their name across to young children, since familiarity takes a long time to establish. As Vakratsas and Ambler (1999, p.31) note, “a 
minimum number of exposures is necessary for the advertisement to have an effect”.

Lack of product familiarity and memory deficits offer some explanation as to why many of the toys advertised were not requested by any of the children in this study. Certainly the Admap (2000) suggestion that 'the visuals are key, words secondary' when advertising to children does not seem to have resulted in production techniques which enhance the memorability of the product name. However, recognition memory at this age is far better than recall (Gunter et al. 1997) and a child would need to explicitly recall a product's name in order to ask for it in a letter. Future studies will include recognition measures in order to tap in to the child's implicit memory. An alternative explanation is that the products themselves may not be appealing and fail to create a desire and that children are more shrewd and sophisticated than the advertisers would believe. However, given the lack of cognitive skills of children in the age group studied here this is unlikely. Finally, the restrictions on advertisements imposed by the ITC, and the self-regulation codes, may be seen here to be working very effectively in preventing pester power. It is unlikely that children would be pestering their parents for advertised toys and yet fail to mention the desired toy in their letter to Santa. What this study does show, however, is that increased exposure to commercials has the effect of making children want more toys in general, rather than specific named products so pester power cannot be totally ruled out. The heavy viewing children in this study may possibly be pestering their parents for the latest type of toys, although not necessarily by name. A similar positive relationship between high viewing and more requests was also found in a cross-cultural study carried out by Robertson, Ward, Gatignon and Klees (1989). Their study also investigated parent-child conflict and found this was higher in families where children watched more television. Therefore, parents who allow their children to watch a lot of TV in order to give themselves an 'easier' life may, in fact, be creating more problems for themselves in the long run.

The comparison with the Swedish children confirmed that the presence of advertisements on UK television tended to result in more requests generally. Clearly, there may be cultural issues related to this and, ideally, further studies would explore this and take account of the 
Swedish children's television viewing habits. Nonetheless, these data provide a tentative confirmation that increased exposure to commercial television generates more demands from children and, where there are fewer advertisements, children ask for less.

In summary, this study finds that increasing amounts of commercial television watched are matched by an increase in the overall amount of toys requested by children, and an increase in the number of branded products requested. This suggests that there is a general effect of advertising, and young children's susceptibility to the persuasive intent of commercials is reinforced by the lone viewing data. However, with the exception of two well-established products, the paucity of a relationship between the branded products requested and the frequency of televised advertisements for them suggests that advertisements do not have an individual impact on the under-sevens but contribute to a general increase in desire. The implication of this is that a society which exposes young children to many thousands of advertisements every year also has a duty to educate those children in consumer literacy and critical viewing.

\section{$\underline{\text { References }}$}

Admap (2000) Children: Victims or Allies? January, 402. 19-20. Admap Publications.

Aloise-Young, P. A. (1993). The development of self-presentation: self-promotion in 6- to 10year old children. Social Cognition, 11, (2), 201 - 222.

Bennett, M. \& Yeeles, C., (1990). Children's understanding of the self-presentational strategies of ingratiation and self-promotion. European Journal of Social Psychology, 20, 455 - 461.

Berry, G. L. \& Keiko Asamen, J. (1993) Children and television: Images in a changing sociocultural world. London: Sage. 
Collins, W.A. \& Wellman, H. (1982). Social scripts and developmental patterns in comprehension of televised narratives. Communication Research, 9, 380 - 398.

Dorr, A. (1986) Television and children: A special medium for a special audience. Beverley Hills, CA: Sage.

Faul, F. \& Erdfelder, E. (1992). GPOWER: A priori, post-hoc, and compromise power analyses for MS-DOS [Computer program]. Bonn: Bonn University, Dept. of Psychology.

Flavell, J.H., Flavell, E.R., Gree, F.L., \& Korfmacher, J. E. (1990). Do young children think of television images as pictures or as real objects? Journal of Broadcasting and Electronic Media, 34, 399-417.

Gaines, L. \& Esserman, J. F. (1981). A quantitative study of young children's comprehension of television programmes and commercials, in J. F. Esserman (ed.), Television Advertising and Children, New York: Child Research Service, 1981).

Greenberg, B.S., Fazal, S. \& Wober, M. (1986). Children’s views on advertising. London: Independent Broadcasting Authority (now the Independent Television Commission).

Gunter, B. \& McAleer, J. (1997). Children and television. 2nd Ed. London: Routledge.

Henricksen, L. (1996). Naive theories of buying and selling: Implications for teaching critical viewing skills. Journal of Applied Communication Research, 24, 2, 93 - 109.

Hite, R.E. \& Eck, R. (1987) Advertising to children: Attitudes of Business vs Consumers. Journal of Advertising Research. October/November, 40-53. 
Hite, C.E. \& Hite, R.E. (1994). Reliance on brand by young children. Journal of the Market Research Society, 37, 3, 185 - 193.

Huston, A.C. \& Wright, J.C. (1998). Mass media and children’s development. In W. Damon (Gen. Ed.), I. E. Sigel, \& K.A.Renninger (Vol. Eds.), Handbook of child psychology: Vol. 4, Child psychology in practice, 999-1058.

Jaglom, L. M. \& Gardner, H. (1981). The pre-school television viewers as anthropologist. In H. L. Kelly \& H. Gardner (Eds.) Viewing children through television (pp. 9 - 30). San Francisco: Jossey-Bass.

Karmiloff-Smith, A. (1992) Beyond Modularity: a developmental perspective on cognitive science. MA: MIT Press.

Levin, S.R., Petros, T.V. \& Petrella, F.W. (1982). Preschoolers' awareness of television advertising. Child Development, 53, 933-937.

Linn, M.C., de Benedictis, T., \& Delucchi, K. (1982). Adolescent reasoning about advertisements: Preliminary investigations. Child Development, 56, 1479 -1498.

Livingstone, S. \& Bovill, D. (1999). Social perspectives: Have the media ruined childhood? Interactions, Vol. 6, No. 6 (Nov) pp. 36 - 41.

Macklin, C. (1994) The effects of an advertising retrieval cue on young children's memory and brand evaluations. Psychology and Marketing, 11,3, 291 - 311. 
Pine, K. J. \& Messer, D. J. (1999). What children do and what children know: Looking beyond success using Karmiloff-Smith’s RR framework. New Ideas in Psychology, 17, 17 - 30.

Robertson, T.S. \& Rossiter, J.R. (1976) Short-run advertising effects on children: a field study. Journal of Marketing Research, 13, 1, 68-70.

Robertson, T.S., Ward, S., Gatignon, H. \& Klees, D. (1989). Advertising and children: A cross cultural study. Communication Research, 16, 4, 459 -485.

Rossiter, J.R. \& Robertson, T.S. (1974). Canonical Analysis of developmental, social and experiential factors in children’s comprehension of television advertising. Journal of Genetic Psychology, 129, 317-327.

Sharp, T., Dyer, R. \& Divita, S. (1976). An experimental test of the harmful effects of premiumorientated commercials on children. Journal of Advertising Research, $\underline{3,} 1$ - 11.

Vakratsas, D. \& Ambler, T. (1999) How advertising works: what do we really know? Journal of Marketing, 63, 26-43.

Ward, Wackman \& Wartella, (1977). How children learn to buy. Beverley Hill, Ca.:Sage.

Young, B. (1998) Emulation, Fears and Understanding: A review of recent research on children and television advertising. London: Independent Television Commission. 
